\title{
Tunable All-in-Fiber Waveplates Based on Negative Dielectric Liquid Crystal Photonic Bandgap Fibers
}

Wei, Lei; Eskildsen, Lars; Weirich, Johannes; Scolari, Lara; Alkeskjold, Thomas Tanggaard; Bjarklev, Anders Overgaard

Published in:

The 21st Annual Meeting of the IEEE Lasers \& Electro-Optics Society

Link to article, DOI:

10.1109/LEOS.2008.4688477

Publication date:

2008

Document Version

Publisher's PDF, also known as Version of record

Link back to DTU Orbit

Citation (APA):

Wei, L., Eskildsen, L., Weirich, J., Scolari, L., Alkeskjold, T. T., \& Bjarklev, A. O. (2008). Tunable All-in-Fiber Waveplates Based on Negative Dielectric Liquid Crystal Photonic Bandgap Fibers. In The 21st Annual Meeting of the IEEE Lasers \& Electro-Optics Society (pp. MEI). IEEE Press. https://doi.org/10.1109/LEOS.2008.4688477

\section{General rights}

Copyright and moral rights for the publications made accessible in the public portal are retained by the authors and/or other copyright owners and it is a condition of accessing publications that users recognise and abide by the legal requirements associated with these rights.

- Users may download and print one copy of any publication from the public portal for the purpose of private study or research.

- You may not further distribute the material or use it for any profit-making activity or commercial gain

- You may freely distribute the URL identifying the publication in the public portal 


\title{
Tunable All-in-Fiber Waveplates Based on Negative Dielectric Liquid Crystal Photonic Bandgap Fibers
}

\author{
L. Wei ${ }^{1}$, L. Eskildsen ${ }^{1}$, J. Weirich ${ }^{1}$, L. Scolari ${ }^{1}$, T. T. Alkeskjold ${ }^{2}$, and A. Bjarklev ${ }^{1}$ \\ ${ }^{1}$ DTU Fotonik, Department of Photonics Engineering, Technical University of Denmark, DK-2800 Lyngby, Denmark \\ ${ }^{2}$ Crystal Fibre A/S, Blokken 84, DK-3460 Birkerød, Denmark \\ lewe@,fotonik.dtu.dk
}

\begin{abstract}
Tunable all-in-fiber waveplates based on negative dielectric liquid crystal photonic bandgap fibers are presented. The birefringence can be tuned electrically and thermally to work as a quarter-wave or a half-wave plate in the range $1520 \mathrm{~nm}$ $1580 \mathrm{~nm}$.
\end{abstract}

\section{INTRODUCTION}

Photonic Crystal Fibers (PCFs) are microstructured waveguides with a large number of air holes running along the length of the fiber and usually located in the cladding region [1]. An initial index-guiding PCF can be converted to a bandgap-guiding PCF by infiltrating the air holes with Liquid Crystals (LCs), which allow for optical [2], thermal [3, 4], and electrical [4-7] tuning. A continuously tunable birefringence controller with phase shift of $60^{\circ}$ by using a dual-frequency Liquid Crystal filled Photonic BandGap (LCPBG) fibers has been proposed [7]. The behaviour of LCs with negative dielectric anisotropy, whose molecules tend to reorient perpendicular to the direction of the electric field, has also been investigated recently [8]. Here, we experimentally demonstrate continuously tunable waveplates by using negative dielectric anisotropy LC in the wavelength range $1520 \mathrm{~nm}-1580 \mathrm{~nm}$. The birefringence of these devices can be tuned thermally and electrically for realizing both quarter and half waveplates.

\section{EXPERIMENTAL RESULTS}

The fiber used in the experiments is a Large Mode Area PCF (LMA-13, Crystal Fibre A/S), with a solid core surrounded by 5 rings of air holes arranged in a triangular lattice. The hole diameter, inter-hole distance and outer fiber diameter are $4.3 \mu \mathrm{m}, 8.5 \mu \mathrm{m}$ and $125 \mu \mathrm{m}$, respectively. A negative dielectric LC MLC-6608 (Merck, Germany) with a dielectric anisotropy $\Delta \varepsilon=-4.2$, having a $90^{\circ}$ splay alignment as shown in the bottom inset of Fig. 1, is infiltrated for $20 \mathrm{~mm}$ of the length of the fiber by using capillary forces.

From the previous work [8], we know the lower order bandgap starting at $1507 \mathrm{~nm}$ is shifted towards shorter wavelengths by increasing temperature. During the shift, the bandgap still covers the $1550 \mathrm{~nm}$ region. Therefore, in this paper we investigate the polarization sensitivity and corresponding activation loss for $1550 \mathrm{~nm}$ firstly. Broadband light from a supercontinuum source (SuperK, Koheras A/S) is collimated using a fiber-coupled lens and polarized using a broadband Glan-Thompson polarizer. The polarized output is

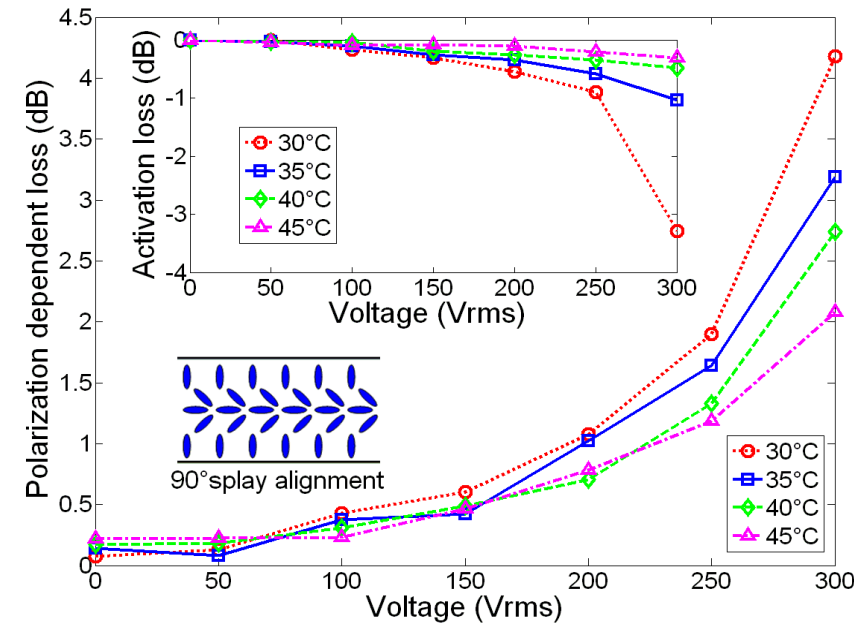

Fig.1 Polarization dependent loss of LMA-13 filled with MLC-6608 at 1550nm for different temperatures. The top inset shows the activation loss at $1550 \mathrm{~nm}$. The bottom inset shows the $90^{\circ}$ splay alignment of MLC-6608.

passed through three achromatic wave plates (quarter, half, quarter) to have full broadband polarization control of the light source in the wavelength range of $1200 \mathrm{~nm}$ to $1650 \mathrm{~nm}$. The polarized beam is coupled into the LMA-13, and then buttcoupled to the LC filled PCF. The transmission spectrum is measured by an optical spectrum analyzer, and normalized to that of the unfilled fiber. The device is driven in bipolar mode by a $1 \mathrm{kHz}$ sine wave. When an electric field is applied, the minimum transmission can be found by adjusting the three wave plates, while the maximum transmission can be obtained by only rotating the half-waveplate $45^{\circ}$ from the position which gives the minimum transmission. Fig. 1 and the top inset of Fig. 1 plot the measured polarization dependent loss (PDL) and activation loss (AL) at $1550 \mathrm{~nm}$ for different temperatures, respectively. At $1550 \mathrm{~nm}$ the $\mathrm{PDL}$ is $4.2 \mathrm{~dB}$ at $300 \mathrm{Vrms}$ and $30^{\circ} \mathrm{C}$. The $\mathrm{AL}$ is lower than $3.5 \mathrm{~dB}$ under the same conditions, and less than $1.0 \mathrm{~dB}$ at higher temperatures. When the temperature increases, PDL and AL are getting smaller. This is because the dielectric anisotropy $\Delta \varepsilon$ decreases as the temperature increases, and the molecules of LC are more difficult to drive or more driving voltage is needed to obtain the same degree of reorientation. For realizing tunable waveplates and birefringence controllers, low PDL and AL are required. $180 \mathrm{Vrms}$ is therefore considered as the maximum driving voltage. For different temperatures, when the device is 


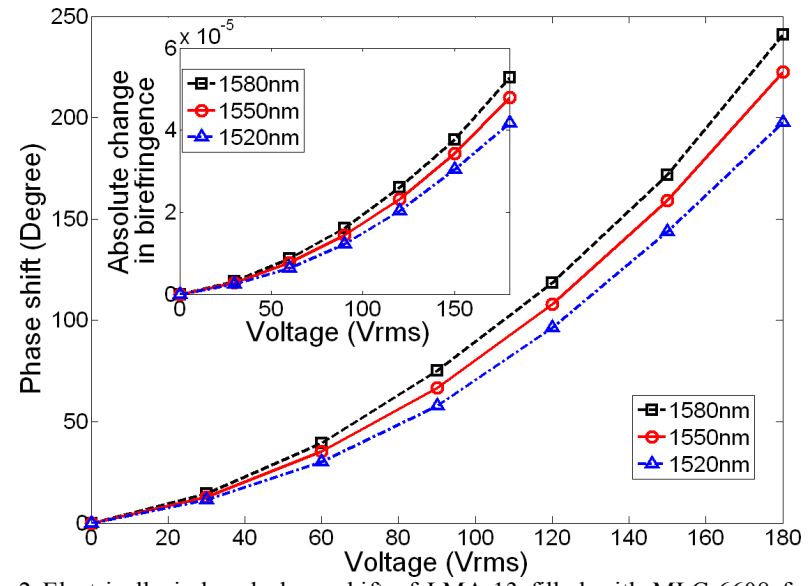

Fig.2 Electrically induced phase shift of LMA-13 filled with MLC-6608 fo different voltages at $30^{\circ} \mathrm{C}$. The inset shows the electrically induced absolute change in birefringence of LMA-13 filled with MLC-6608 for different voltages at $30^{\circ} \mathrm{C}$.

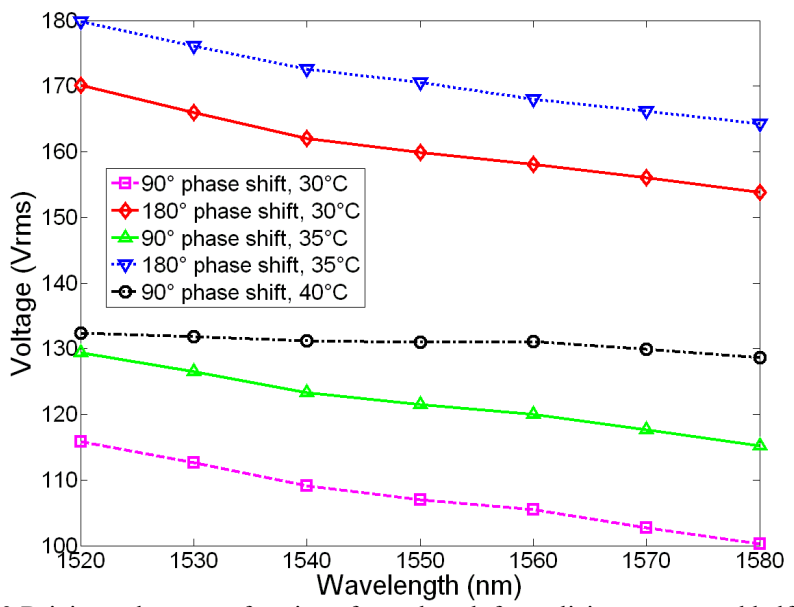

Fig. 3 Driving voltage as a function of wavelength for realizing quarter and half waveplates at different temperatures.

driven by $180 \mathrm{Vrms}$, the maximum $\mathrm{AL}$ is $0.45 \mathrm{~dB}$, while the maximum $\mathrm{PDL}$ is only $0.67 \mathrm{~dB}$ taking the small variation caused by placing and rotating three free space waveplates into account.

When an electric field is applied to the LCPBG fiber, the LC reorients depending on the applied voltage. The two orthogonally polarized guided modes experience different refractive indices compared to the case in which the field is off and this introduces a phase shift between them. This gives an opportunity to develop electrically controlled wave plates and polarization controllers. To demonstrate the electrically induced phase shift and corresponding induced birefringence, a polarized and tunable laser source operating from $1520 \mathrm{~nm}$ to $1620 \mathrm{~nm}$ is connected to the LCPBG fiber through a polarization analyzer. A polarization controller is used to find a polarization state with a transmission spectrum between the maximum and minimum states. The polarization analyzer launches the light in the LCPBG fiber and resolves the output light into the Stokes parameters, which is then plotted on the surface of the Poincaré sphere. Any change inducing a phase shift between the orthogonal polarizations in the fiber device results in a rotation on the sphere. Fig. 2 plots the electrically induced phase shift and corresponding birefringence change of an LMA-13 filled with $20 \mathrm{~mm}$ MLC-6608 as a function of voltage for different wavelengths at $30^{\circ} \mathrm{C}$. A phase shift of $197.8^{\circ}$ can be obtained by applying $180 \mathrm{Vrms}$, which gives a birefringence of $4.17 \times 10^{-5}$ at $1520 \mathrm{~nm}$ as shown in the inset of Fig. 2. More phase shift and birefringence is observed when an input signal with a longer wavelength is launched, e.g. a phase shift of $222.5^{\circ}$ and $241.1^{\circ}$, and a change in birefringence of $4.79 \times 10^{-5}$ and $5.29 \times 10^{-5}$ are obtained for $1550 \mathrm{~nm}$ and $1580 \mathrm{~nm}$, respectively. The same measurement has also been taken for $35^{\circ} \mathrm{C}$ and $40^{\circ} \mathrm{C}$. Fig. 3 plots the driving voltage as a function of wavelength for the device as a quarter-wave plate with $90^{\circ}$ phase shift and a half-wave plate with $180^{\circ}$ phase shift at different temperatures. When working at longer wavelengths, lower voltage is needed to achieve the same phase shift as working at shorter wavelengths. This is because the longwavelength edge is more sensitive to the electric field than the short-wavelength edge of the same bandgap, which is caused by different sensitivity of PBG modes to the electrically induced LC alignment. Maximum driving voltage variation of $16.3 \mathrm{Vrms}$ is observed, when the device performs as a quarterwave and a half-wave plate both at $30^{\circ} \mathrm{C}$ and $35^{\circ} \mathrm{C}$. However, only $3.7 \mathrm{Vrms}$ variation is needed to achieve a stable performance for using it as a quarter-wave plate at $40^{\circ} \mathrm{C}$.

\section{CONCLUSION}

In conclusion, we have experimentally demonstrated the tunable all-in-fiber waveplates based on a PCF infiltrated with a negative dielectric anisotropy LC. The device works in the wavelength range $1520 \mathrm{~nm}-1580 \mathrm{~nm}$, and the birefringence is tuned electrically and thermally to give both a quarter-wave and a half-wave plate operation with less than $0.67 \mathrm{~dB}$ polarization dependent loss and $0.45 \mathrm{~dB}$ activation loss in the temperature range $30^{\circ} \mathrm{C}-40^{\circ} \mathrm{C}$.

\section{REFERENCES}

[1] P. St. J. Russell, "Photonic crystal fibers," Science, vol. 299, pp. 358$362,2003$.

[2] T. T. Alkeskjold, et al., "All-optical modulation in dye doped nematic liquid crystal photonic bandgap fibers," Opt. Express, vol. 12, pp. 5857 5871,2004

[3] T. T. Larsen et al., "Optical devices based on liquid crystal photonic bandgap fibers,” Opt. Express, vol. 11,pp. 2589-2596, 2003.

[4] T. R. Wolinski, et al., "Photonic liquid crystal fibers - a new challenge for fiber optics and liquid crystals photonics", Opto-Electron. Rev., vol. 14, pp. 329-334, 2006.

[5] F. Du, et al., "Electrically tunable liquid-crystal photonic crystal fiber," Appl. Phys. Lett. Vol. 85, pp. 2181-2183, 2004.

[6] M.W. Haakestad, et al., "Electrically tunable photonic bandgap guidance in a liquid crystal filled photonic crystal fiber", IEEE Photonics Technology Letters, vol. 17, pp. 819-821, 2005.

[7] L. Scolari, et al., "Continuously tunable devices based on electrical control of dual-frequency liquid crystal filled photonic bandgap fibers," Opt. Express, vol. 13, pp. 7483-7496, 2005.

[8] L. Wei, et al., "High thermal and electrical tunability of negative dielectric liquid crystals photonic bandgap fibers," Conference on Lasers and Electro-Optics (CLEO 2008), paper id: CThEE5, 2008. 